\title{
A importância das cidades médias e pequenas no ensino de geografia e as políticas curriculares
}

The importance of medium and small cities in geography teaching and the curricular policies

\author{
André de Paula Silva \\ Mestre em Geografia pelo PPGEO/UNIFAL - MG \\ Docente na Educação Básica do Estado de Minas Gerais, Brasil \\ andre.paula@sou.unifal-mg.edu.br \\ Sandra de Castro de Azevedo \\ Doutora em Geografia pela USP/SP \\ Professora na UNIFAL/Minas Gerais, Alfenas, Brasil \\ sandra.azevedo@unifal-mg.edu.br
}

\begin{abstract}
Resumo
O Brasil possui uma quantidade significativa de cidades médias e pequenas. No entanto, a vivência da sala de aula enquanto professor de geografia mostrou que elas, geralmente, não são abordadas no ensino de Geografia. Este trabalho tem como objetivo compreender como a Base Nacional Comum Curricular (BNCC) possibilita a abordagem da temática sobre cidades médias e pequenas no ensino de Geografia. Para alcançar este objetivo, com base no método materialista histórico dialético, utilizou-se como técnicas as análises bibliográfica e documental e aplicação de questionário via email aos professores de Geografia da cidade média de Alfenas e da cidade pequena de Paraguaçu, ambas no Sul de Minas Gerais. Constatou-se que, em nível federal, as realidades dessas cidades são desconsideradas, prevalecendo um enfoque das escalas nacionais e globais. Dessa maneira foi possível constatar que a BNCC aborda um nacional que não representa a realidade de todo o território brasileiro e que também não é organizada de forma que estimule o professor a realizar uma abordagem mais explícita de cidades médias e pequenas.
\end{abstract}

Palavra-chave: BNCC; articulação entre local e global; Currículo Mineiro de Geografia.

\begin{abstract}
Brazil has a significant amount of medium and small cities. However, the classroom experience showed that they are generally not addressed in Geography teaching. This work aims to understand how the Common National Curriculum Base (BNCC) enables the approach of the theme about medium and small cities in Geography teaching. In order to achieve this objective, based on the nondialectical historical-materialist method, the technique used was bibliographic and documental analysis and the application of a questionnaire via e-mail to Geography teachers in the middle town of Alfenas and the small town of Paraguaçu, both in the south of Minas Gerais. It was found that at the federal level, the realities of these cities are disregarded, with a focus on national and global scales prevailing. Thus, it was possible to verify that the BNCC addresses a nation that does not represent the reality of the entire Brazilian territory. It is also not organized to encourage the teacher to adopt a more direct approach to medium and small cities.
\end{abstract}

Keywords: Curriculum Policy; Medium and small cities; Geography Teaching. 


\section{INTRODUÇÃO}

As cidades médias e pequenas tomam grande importância no cenário nacional e estadual, como no caso de Minas Gerais. Assim, estão presentes na articulação entre o local e o global. Todavia, ainda se faz necessário, para complementar a discussão, entender a importância das cidades também para o ensino de Geografia.

Além das numerosas cidades médias e pequenas, em que grande parte da população está inserida, é importante ressaltar que, no atual cenário social em que vivemos, a população brasileira é considerada predominantemente urbana. Conforme o IBGE (2010), a população brasileira residente nas áreas urbanas já era de 84,35\%, com 67 municípios abrangendo $100 \%$ de sua população totalmente urbana, em contrapartida de apenas 9 municípios com uma população acima de $90 \%$ rurais $^{1}$. Já Minas Gerais apresenta uma população urbana de mais de 85\%. No que tange aos municípios de Alfenas e Paraguaçu, estes também seguem o padrão nacional e estadual. Entretanto, Alfenas até supera estes padrões com uma população urbana de 93\%, enquanto Paraguaçu possui uma população 82\% (IBGE, 2010). O que evidencia que, em todos os cenários e escalas territoriais, as cidades se configuram com um grande contingente populacional, abrigando a grande maioria da população.

Dessa maneira, fica evidente a importância de se considerar estes espaços, os espaços das cidades, no ensino de Geografia. Conforme Cavalcanti (2011), as cidades se configuram como um produto de diversos conflitos dialéticos, em que o global e local está presente, assim como outros conflitos das mais diversas formas.

Grande parte das pessoas atualmente vive em cidades, que são locais complexos com modos de vida que se padronizou, sobretudo no mundo ocidental. Tais aspectos afetam todas essas pessoas, embora haja uma diversidade de grupos, uma multiplicidade de redes sociais, de manifestações culturais, em disputa e em conflito nesses mesmos locais. Com isso, as cidades se produzem numa dialética do local/global, do homogêneo/heterogêneo, da inclusão/exclusão, para que seus habitantes pratiquem a vida coletiva, compartilhando desejos, necessidades e problemas cotidianos (CAVALTANTI, 2011, p. 2).

Neste sentido, as cidades se caracterizam como um espaço de vivência de suma importância para alunos e professores, visto que estão articuladas, pelas suas dinâmicas, às dinâmicas e acontecimentos globais. Ou seja, as cidades se tornam a materialização socioespacial da articulação entre o local e o global, influenciando totalmente o cotidiano dos alunos. Assim, considerá-las no ensino de geografia não se torna somente um aspecto importante, mas uma real necessidade no

${ }^{1}$ https://agenciadenoticias.ibge.gov.br/agencia-sala-de-imprensa/2013-agencia-de-noticias/releases/1393-asi-censo2010 . 
cenário atual de globalização em que nossa sociedade vive, como lembram Callai, Cavalcanti e Castellar (2007).

A cidade é aqui considerada como tema do ensino porque, em primeiro lugar, é a referência básica para a vida cotidiana da maior parte das pessoas. Ela é local de moradia de um grande contingente populacional; nela se produz e se decide a produção de uma grande parte de mercadorias e de serviços; nela circulam pessoas e bens; nela, também, se produz um modo de vida (LEFEBVRE, 1991; CARLOS, 1992). Todo esse movimento mostra que na cidade estão materializadas, por um lado, a dinâmica do capital e, por outro, a dinâmica da sociedade; ambas se expressam contraditoriamente na prática cotidiana dos cidadãos (CALLAI; CAVALCANTI; CASTELLAR, 2007, p. 93).

Dessa maneira, o fato de tratar as cidades no ensino de geografia não se torna o suficiente. Pois, como visto anteriormente, as cidades fazem parte de um processo dialético e articulado entre as dinâmicas socioespaciais locais e globais. Visto isso, é necessário que os conteúdos que tratem as cidades também devem procurar tratar desta articulação, mostrando como a escala local, presente na realidade do aluno, se relaciona e articula com a escala global, podendo, como salienta Cavalcanti (2011), atribuir elementos para que o aluno faça uma análise crítica de sua realidade e entendê-la como parte deste processo.

Emerge, então, o destaque para o estudo dessa temática no cotidiano da sala de aula, não num enfoque convencional que prioriza informações e dados da realidade, mas priorizando o objetivo de formação de conceito, o que exige, antes de tudo, que os alunos possam aprender a analisar sua realidade local em relação a contextos mais globais. Deve-se levar em consideração, portanto, o local, visando propiciar a construção pelo aluno de um quadro de referências mais geral que lhe permita fazer análises críticas. No conjunto de temas que ajudam a Geografia a mediar um conceito de cidade para a vida cotidiana devem estar incluídos aqueles que se referem aos meios de socialização dos alunos e que representem sua geografia vivida, como cultura juvenil, linguagem e suas expressões, seus espaços de consumo, lazer, mercado, imagens, sons, ritmos, tecnologia, trabalho, códigos, lugares multiculturais, tempo e espaço dos sujeitos jovens adolescentes, construindo e estabelecendo práticas sócioespaciais (CAVALCANTI, 2011, p. 5).

Assim sendo, percebe-se a clara importância que as cidades, como conteúdo a ser trabalhado no ensino de geografia, torna-se cada vez mais importante. Temas e conteúdo em escala local sempre podem fornecer melhores elementos para que os educandos possam construir o conhecimento de maneira mais concreta. O principal objetivo de se levar em conta as cidades no ensino de geografia é justamente mostrar para os alunos como os conteúdos em escala local e seu cotidiano estão articulados com as dinâmicas de escala global e, como designa Sacramento (2017), contribuindo para que os alunos construam o conhecimento próximo de suas realidades e de forma autônoma.

As concepções de ensinar Geografia e a cidade, segundo Sacramento (2012, 2014), têm por objetivo pensar uma educação geográfica que possibilite articular os conceitos e os conteúdos na mediação do conhecimento, a fim de analisar espacialmente as diferentes concepções espaciais, que podem ser histórico-patrimoniais, ambientais, morfológicas; e também como função de escala, em que o cidadão atua como protagonista na construção do seu conhecimento (SACRAMENTO, 2017, p. 108).

É possível, dessa forma, perceber que as cidades se tornam um tema não só necessário, mas imprescindível para o ensino de geografia. Isto se dá, como evidenciado, não só pelo grande 
contingente populacional que as cidades abrigam, mas pela sua importância nas dinâmicas socioespaciais e na articulação entra a escala local e global, deixando evidente sua relevância no ensino,

Entretanto, reconhecer e saber de sua importância para o ensino de geografia é apenas o ponto de partida. Torna-se necessário ainda saber como as políticas curriculares de geografia, enquanto estruturadoras do conhecimento nas escolas, tratam as cidades, e aqui se delimita para as cidades médias e pequenas em questão e como suas realidades são trabalhadas. Para isso, foram aplicados questionários via e-mail com professores das escolas públicas da rede estadual de Minas Gerais atuantes no ensino fundamental II da cidade média de Alfenas - MG e na cidade pequena de Paraguaçu - MG para analisar suas percepções e realizar um paralelo com o que as políticas curriculares, no caso a Base Nacional Comum Curricular propõe e dessa forma ter uma análise mais completa e próxima da realidade pesquisada.

\section{AS POLÍTICAS CURRICULARES, O GLOBAL E O LOCAL}

As políticas educacionais brasileiras são influenciadas por órgãos mundiais e pelo processo econômico global vigente, desta forma, elas fazem parte de um projeto social, pois, além da esfera educacional, abarcam as esferas econômicas, sociais e culturais, tratando-se, então, de um importante elemento na atual sociedade.

Nesta pesquisa, entende-se por políticas públicas em educação todas aquelas ações, medidas e iniciativas das diferentes esferas do poder público na área da educação. Assim sendo, Fávero, Horta e Frigotto (1992) reforçam a ideia de que para se pensar em políticas educacionais é necessário também pensar que tais políticas devem atender às demandas atuais da sociedade brasileira em todas as suas dimensões. Entretanto, há um propósito de não se entender as políticas em sua verdadeira essência, ou seja, como práticas sociais que se constroem ao longo do tempo, de modo complexo, entre as relações sociais, econômicas e culturais.

Para adentrar de forma mais profunda ao universo dessas Políticas, faz-se necessário uma periodização no país. Silva (2012) expõe três principais períodos de estabelecimento das Políticas Públicas educacionais pós-guerra: a primeira fase surge logo após a Segunda Guerra Mundial, em que algumas instituições surgem com o objetivo de recuperação econômica de algumas nações, como a UNESCO, Banco Mundial, Banco Internacional de Desenvolvimento e a Organização dos Estados Americanos - fase marcada por diversas intervenções de instituições financeiras em diversos países em prol da recuperação econômica. Além disso, tal período foi marcado por índices muito baixos em educação, o que, segundo teorias, justificava a estagnação de tais nações. 
Em um segundo período, entre 1970 e 1989, surgiu o que Alves (2012) chama de racionalização das Políticas Públicas - Período marcado por governos autoritários e grandes empréstimos atribuídos a projetos por instituições, como o Banco Mundial e o Fundo Monetário Internacional. No mesmo contexto, no Brasil, espalhavam-se movimentos e lutas sociais por direitos básicos e democracia, porém, a educação pública ia de mal a pior, com índices de reprovação e abandono cada vez maiores e condições precárias de trabalho docente, o que mudou muito pouco até os dias de hoje.

Em um terceiro momento, entre 1989 e 2010, Silva (2012) designa como um momento de relação transnacional entre os Estados, em que, pelo momento de Globalização econômica, as Políticas Públicas e, com as educacionais não foi diferente, se encaixam num projeto de racionalização e flexibilidade ao capital cada vez maior. Com isso, os interesses em suprir as demandas mercadológicas estão cada vez mais presentes nas Políticas em educação, em detrimento de uma educação voltada para as questões sociais e a realidade de cada educando. Isso faz parte de um projeto em que cada vez mais a educação entra em uma crise, esse é o objetivo para que a Educação também fique à mercê do capital. Desta forma, percebe-se que o jogo em que se encontram as Políticas educacionais é totalmente unilateral, apesar das resistências apresentadas por algumas organizações científicas, sindicatos e movimentos sociais.

As políticas educacionais conduzem as reformas educacionais no Brasil. Um dos elementos muito enfatizado nessas reformas é o currículo, que na maioria das vezes é prescrito por meio de políticas curriculares.

Um importante exemplo é a Lei de Diretrizes e Bases da Educação Nacional (LDB) para a educação brasileira aprovada em 1996. Na LDB é previsto que a União em parceria com os estados e municípios devem estabelecer as orientações curriculares que serão referência para os currículos e seus conteúdos, inclusive que tais orientações, inseridas em contextos diversos, contenham partes diversificadas para responder às demandas locais e regionais.

Art.9...

IV - estabelecer, em colaboração com os Estados, o Distrito Federal e os Municípios, competências e diretrizes para a educação infantil, o ensino fundamental e o ensino médio, que nortearão os currículos e seus conteúdos mínimos, de modo a assegurar formação básica comum; (BRASIL, 1996).

Art. 26. Os currículos do ensino fundamental e médio devem ter uma base nacional comum, a ser complementada, em cada sistema de ensino e estabelecimento escolar, por uma parte diversificada, exigida pelas características regionais e locais da sociedade, da cultura, da economia e da clientela. (BRASIL, 1996, p. 4).

Para entender as políticas curriculares de Geografia no âmbito nacional e, consequentemente, o Currículo de Geografia no âmbito estadual, ou seja, o conteúdo de Geografia estruturado e sistematizado a se ensinar nas instituições escolares, é inevitável relacionar com o momento econômico em que a sociedade está inserida e como suas necessidades e interesses podem 
exercer influência direta ou indiretamente nas políticas públicas e, consequentemente, na própria escola. Por meio das prescrições das propostas curriculares e dos currículos estaduais, que são construídos em um processo de homogeneização, é possível compreender como as dinâmicas econômicas globais podem impactar nas práticas escolares de cidades pequenas e médias.

Nesse contexto, surge assim os PCN (Parâmetros Curriculares Nacionais), com objetivo de nortear os conteúdos a serem ministrados nas escolas por todo o país, apesar de não ser uma política de imposição de conteúdo e somente parâmetros para auxiliar os professores, interferiram nas avaliações nacionais e no Programa Nacional do Livro Didático. Seguindo a LDB e os PCN, o estado de Minas Gerais elabora o Currículo Básico Comum (CBC), com o objetivo de adaptar as demandas do estado ao PCN.

Em 2018, foi homologada a BNCC (Base Nacional Comum Curricular). A BNCC surge com o compromisso de implementar uma educação integrada e articulada e também com o intuito de corresponder com o que estava previsto no Plano Nacional de Educação de 2014.

7.1. estabelecer e implantar, mediante pactuação interfederativa, diretrizes pedagógicas para a educação básica e a base nacional comum dos currículos, com direitos e objetivos de aprendizagem e desenvolvimento dos(as) alunos(as) para cada ano do ensino fundamental e médio, respeitada a diversidade regional, estadual e local; (BRASIL,2014, p.61, grifo nosso).

Em consonância com a BNCC, em nível estadual, surge o Currículo Referência de Minas Gerais em que, teoricamente, o objetivo seria adequar os conteúdos da BNCC para as realidades do estado de Minas Gerais.

As propostas curriculares nacionais e os currículos estaduais são prescrições de conteúdo, competências e habilidades selecionados, pautados em um projeto de educação que em sua maioria não dialoga com a realidade das escolas. Ademais, analisar o currículo, como lembra Sacristàn (2013), torna-se fundamental.

A importância fundamental do currículo para a sociedade reside no fato de que ele é a expressão do projeto cultural e educacional que as instituições de educação dizem que irão desenvolver com os alunos (e para eles) aquilo que consideram adequado. Por meio desse projeto institucional, são expressadas forças, interesses ou valores e preferências da sociedade, de determinados setores sociais, das famílias, dos grupos políticos etc. Esse projeto idealizado não costuma coincidir com a realidade que nos é dada. (SACRISTÀN, 2013, p. 24).

Como expressam um projeto social, fica evidente que os textos curriculares são permeados por disputas de interesses. Pensando no impacto do currículo no trabalho dos professores, Arroyo (2007, p.19) afirma que:

A organização de nosso trabalho é condicionada pela organização escolar que, por sua vez, é inseparável da organização curricular.

$\mathrm{O}$ que ensinamos, como ensinamos, com que ordem, sequência, lógicas e em que tempos e espaços são os condicionantes de nossa docência, realizam-nos como profissionais ou limitam-nos e escravizam-nos a cargas horárias, a duplicar turnos, a trabalhar com centenas de alunos por semana. Sermos fiéis ao currículo, às competências que prioriza, às precedências e hierarquias e a toda essa engrenagem montada em nosso trabalho tem estreita 
relação com os conteúdos privilegiados e selecionados, sobretudo, com as lógicas em que estão organizados no currículo.

Todavia, para entender todos os agentes e como se dá esse processo, é necessário recorrer à perspectiva dialética, uma vez que, como nos lembra Santos (2012), esta abordagem permite compreender a complexa relação entre as determinações globais da sociedade - entendida aqui como o projeto expresso nos textos curriculares - e as singularidades históricas e locais em que este tipo de política é implementada.

As reformas educacionais iniciadas nos anos 1990, assim como o movimento de implementação da BNCC, como designam Mota e Maués (2014); Triches e De Miranda Aranda (2016) e Girotto (2017), possuem uma relação direta com as políticas do Banco Mundial. O que é possível ser constatado analisando o documento do próprio órgão publicado em 1995, em que deixa claro a importância de um currículo nacional para limitar a autoridade dos docentes e ser a principal base para resultados de avaliações, deixando evidente uma ideia de controle.

\begin{abstract}
Para obter a flexibilidade necessária, a gestão escolar (diretores e órgãos governamentais) devem ter autoridade para alocar recursos. Isso inclui a autoridade para contratar pessoas e determinar algumas coisas como o horário do dia escolar, a duração do ano escolar e a linguagem de instrução, para se adequar às condições locais. Essa autoridade aumentará a eficiência do aprendizado. Os professores devem ter autoridade para determinar as práticas de sala de aula, com limites definidos por um amplo currículo nacional, incentivado por exames, e monitorado e apoiado por padrões, avaliações de aprendizagem e inspetores escolares. Finalmente, os funcionários da escola devem prestar contas à comunidade local (WORLD BANK, WASHINGTON, DC, p. 126, 1995, tradução nossa).
\end{abstract}

Isto ainda, como salienta Oliveira (2016), torna-se mais relevante, pois como se sabe, o Banco Mundial se configura como a principal fonte de financiamentos de países com déficits no ingresso escolar e, dessa maneira, seu intuito é trabalhar em projeto com objetivo de universalizar a educação para combater a pobreza nestes países. Em consonância com o Banco Mundial, o Relatório para a UNESCO da Comissão Internacional Sobre a Educação Para o Século XXI.

Assim se justifica essencialmente o papel do Estado enquanto representante da coletividade no seu conjunto, numa sociedade plural e baseada em parcerias, onde a educação se desenvolve ao longo de toda a vida. Esse papel diz respeito, principalmente, às opções de sociedade que imprimem a sua marca na educação, mas também à regulamentação do conjunto do sistema, assim como à promoção do valor da educação. Não deve, porém, ser exercido como um monopólio estrito. É mais um canalizar de energias, um valorizar de iniciativas e um criar de condições para a emergência de novas sinergias. Corresponde, igualmente, a uma exigência de equidade e de qualidade em matéria de educação. Na lógica da equidade e do respeito pelo direito à educação trata-se, pelo menos, de evitar que o acesso à educação seja recusado a determinadas pessoas ou grupos sociais; é sobretudo importante que o Estado possa ter um papel redistributivo, principalmente em favor de grupos minoritários ou desfavorecidos. A garantia da qualidade da educação supõe, por outro lado, que se elaborem normas globais e que se instituam meios de controle (DELORS; NANZHAO, 1998, p. 175).

Neste trecho é possível constatar a concordância com as ideias do Banco Mundial, principalmente no que se refere ao controle que estas instituições procuram em demasia citar em suas 
propostas e mais especificamente no relatório para a Unesco, que enfatiza a contradição de se propor uma melhoria na qualidade de vida das sociedades em vulnerabilidade e ao mesmo tempo impor normas globais de controle, evidenciando que a principal preocupação está mais em controlar estas sociedades e submetê-las às lógicas e dinâmicas do modo de produção capitalista. Tudo isso reforça os princípios de eficácia e eficiência na oferta de uma educação com pouco investimento e maior regulação e menos em de fato exercer o desenvolvimento social, afinal o projeto de educação proposto segue a linha do capital humano e não de uma educação para a vida.

Outro órgão importante que segue em consonância com as instituições internacionais citadas é a Comissão Econômica da América Latina e Caribe (CEPAL) que, em seu relatório mais recente sobre os desafios da juventude, trabalho e educação frente às competências e habilidades do século XXI, evidencia a importância de que os sistemas educacionais da América Latina proporcionem o desenvolvimento de habilidade e competências ligadas ao mundo do trabalho e à quarta revolução industrial.

Este documento buscou fundamentar a necessidade de repensar as prioridades das ofertas educacionais e curriculares para a Ibero-América, a fim de incorporar o desenvolvimento e fortalecimento das habilidades que serão exigidas com base nas mudanças no mundo do trabalho após a quarta revolução industrial e os compromissos assumidos no âmbito da Agenda 2030 para o Desenvolvimento Sustentável. Esta é importante para toda a oferta formativa e é um desafio que se soma à necessidade de reverter e superar o atraso e as desigualdades na educação nos países da região (CEPAL, 2020, p. 85, tradução nossa).

Para que as políticas curriculares sejam efetivadas, o mesmo documento explicita a importância de se incorporar esta forma de pensar o sistema educacional também ao corpo docente, por meio de formação inicial e continuada, articulando as políticas educacionais, curriculares e de avaliação, ou seja, totalmente consoante com os projetos da UNESCO e Banco Mundial de um controle total do sistema educacional pautado em um discurso de diminuição da pobreza, priorizando o termo equidade no continente e, ao mesmo tempo, um controle do sistema aliado aos interesses do modo de produção capitalista e da globalização pelo foco no desenvolvimento de habilidades e competências.

É essencial que a formação de professores, inicial e continuada, esteja associada às habilidades e competências necessárias para os jovens se prepararem para um mundo em contínua evolução. Ou seja, apesar da existência de uma narrativa internacional sobre competências em contexto educacional, que tem sido utilizado de forma significativa na legislação nacional, a aplicação de modelos educacionais focados em competências continua sendo uma prática em curso, cuja consolidação requer uma articulação ao nível das políticas educacionais, políticas curriculares e de avaliação (CEPAL, 2020, p. 91, tradução nossa).

No Brasil, as Diretrizes Curriculares de Formação de professores, em 2015, já indicavam a obrigatoriedade em considerar a BNCC nos cursos de formação de professores e, em 2019, foram aprovadas novas diretrizes que obrigam os Projetos Pedagógicos de Cursos de Graduação em Licenciatura a atenderem todas as competências presentes na BNCC. 
Art. $2^{o}$ A formação docente pressupõe o desenvolvimento, pelo licenciando, das competências gerais previstas na BNCC-Educação Básica, bem como das aprendizagens essenciais a serem garantidas aos estudantes, quanto aos aspectos intelectual, físico, cultural, social e emocional de sua formação, tendo como perspectiva o desenvolvimento pleno das pessoas, visando à Educação Integral.

Art. $3^{\circ}$ Com base nos mesmos princípios das competências gerais estabelecidas pela BNCC, é requerido do licenciando o desenvolvimento das correspondentes competências gerais docentes (BRASIL, 2019, p.2)

Ou seja, a formação inicial do professor já será pautada na BNCC, levando o professor à aceitação de um currículo prescrito, o que limita assim uma diversidade de formação e de formas de pensar a Geografia e a Educação, formando professores com objetivo único de aplicar a BNCC. E essa padronização também foi ampliada para a formação continuada,

Art. $2^{\circ}$ As presentes Diretrizes Curriculares Nacionais, articuladamente com a BNCFormação Continuada, têm como referência a implantação da Base Nacional Comum Curricular da Educação Básica (BNCC), instituída pelas Resoluções CNE/CP n 2, de 22 de dezembro de 2017 e a Resolução $\mathrm{CNE} / \mathrm{CP}$ n$^{\circ}$ 4, de 17 de dezembro de 2018, e da Base Nacional Comum para a Formação Inicial de Professores da Educação Básica (BNCFormação), instituída pela Resolução CNE/CP n ${ }^{\circ}$ 2, de 20 de dezembro de 2019. (BRASIL, 2020, p.2)

Desta forma fica explícito que a BNCC não é só uma proposta curricular que deve ser adaptada pelos estados e municípios respeitando a diversidade nacional, mas é parte de um projeto de padronização da educação, que se inicia com a aprovação da proposta curricular, nacional, já permeada pelo controle, visto que apresenta Unidades Temáticas, Objetos de Conhecimento e habilidades, os quais estão sempre presentes nos documentos e propostas destas instituições internacionais como elementos básicos para as propostas curriculares. Avança para o controle da formação inicial de professores para garantir que o professor não vai deixar de seguir a BNCC, avança para a formação continuada, todo esse movimento embasado com um discurso de redução da desigualdade da educação.

É explícito na BNCC os princípios conciliando com as premissas destas instituições. No documento pode se notar um discurso similar com as instituições internacionais, com a ideia de que as práticas pedagógicas e o currículo devem sempre trabalhar a superação das desigualdades e, mais uma vez, afirmando o discurso da equidade.

Diante desse quadro, as decisões curriculares e didático-pedagógicas das Secretarias de Educação, o planejamento do trabalho anual das instituições escolares e as rotinas e os eventos do cotidiano escolar devem levar em consideração a necessidade de superação dessas desigualdades. Para isso, os sistemas e redes de ensino e as instituições escolares devem se planejar com um claro foco na equidade, que pressupõe reconhecer que as necessidades dos estudantes são diferentes (BRASIL, 2018, p. 15).

Não muito diferente, o Currículo Referência de Minas Gerais (CRMG) também se articula com as premissas das instituições internacionais e da BNCC, visto que um discurso semelhante pode ser identificado no documento. 
Pensar uma educação para a equidade é pensar em igualdade de oportunidades, numa educação focada na redução das desigualdades e numa lógica libertadora, que rompa o vazio de serviços públicos a uma significativa parcela da população, que, historicamente, é periférica.

Antes de adentrarmos nos parâmetros que embasam o enfoque deste trecho do documento, é importante salientarmos a motivação da escolha do termo equidade. Por que não igualdade? Acreditamos que há igualdade numa ação para a equidade, mas que está vai além e carrega consigo a importante ênfase da justiça social (MINAS GERAIS, 2018, p. 20).

A análise da BNCC (esfera nacional), evidencia que as premissas das instituições internacionais (esfera global), como a propagação da ideia de atenuação das desigualdades, ligada à inserção na educação formal com objetivo de uma possibilidade de ingresso no mercado de trabalho e não à desigualdade social, base do sistema capitalista, e também a propagação da ideia do controle dos sistemas educacionais por meio de um currículo prescrito e de avaliações, estão articuladas com as escalas locais, visto que o currículo estadual atingirá as mais diversas cidades do estado.

Desta forma, faz-se necessário entender como os documentos nacionais e estaduais tratam as médias e pequenas cidades, visto que seu movimento de implementação possui uma articulação estadual e municipal. Isto posto, é possível reconhecer que através de todo um processo histórico permeado de contradições e interesses, os textos curriculares foram produzidos. Desde seu início, as instituições internacionais como Unesco, Banco Mundial, Fundo Monetário Internacional e CEPAL procuraram sempre intervir nas políticas em educação. Logo, é possível perceber que os textos curriculares também se inserem no contexto que Sposito (2010) chama de induzido, uma vez que ao longo do tempo, sob o esteio da globalização as relações internacionais, intensificaram-se cada vez mais e, como já dito, por meio das instituições internacionais - tratadas aqui como indutor - os textos curriculares paulatinamente passaram a responder às suas demandas, parâmetros e exigências, tornando-se, dessa forma, como afirma Frigotto, Ivo e Ieda (2017) uma barriga de aluguel dessas instituições.

Tais instituições sempre estiveram engajadas em apoiar a aprovação de uma nova base curricular. Conforme relata Macedo (2014), quando os blocos econômicos presentes na América Latina se iniciaram, já demandavam padronizações curriculares educacionais e, a partir de meados de 1990, diversas empresas e instituições se propuseram também a exercer pressão para formulação de bases educacionais.

Paralelamente, agentes sociais privados apareciam no cenário da educação, buscando interferir nas políticas públicas para a educação também com perspectivas de maior controle sobre os currículos. Fundações ligadas a conglomerados financeiros como Roberto Marinho, Victor Civita, Airton Senna e Lemann, empresas como Natura, Gerdau e Volkswagen, grupos educacionais como CENPEC e "movimentos" como o Todos pela Educação são alguns dos exemplos. As demandas de agentes privados como estes não são exclusividade do Brasil, nem podem ser localizadas claramente no tempo (MACEDO, 2014, p. 1533).

Com isso, fica claro que as instituições financeiras, grandes empresas e organizações estão historicamente empenhadas em reformas educacionais. Não por interesses sociais ou pedagógicos, 
mas, antes de tudo, por interesses mercadológicos, com o intuito de adaptar cada vez mais o sistema educacional às dinâmicas capitalistas e empresariais, ou seja, a interesses hegemônicos. Assim, ressaltam Triches e Aranda (2016), quando explanam sobre a influência do Movimento Todos Pela Educação e da Fundação Lemann na aprovação da BNCC.

Ao atribuir a esses dois órgãos a função da criação da BNCC, é possível compreender quais as vozes que foram ouvidas e quais interesses foram atendidos no processo de elaboração do documento da BNCC. Nesses termos, Freitas (1992) contribui com o debate quando afirma que não é possível estarmos 'todos juntos pela educação', quando os interesses hegemônicos dos empresários reduzem a educação a produzir o trabalhador que está sendo esperado na porta das empresas, tendo em vista que a educação de qualidade tem que ser mais que isso (TRICHES; ARANDA, 2016, p. 12).

À vista disso, as cidades médias e pequenas tornam-se espaços locais de efetivação e prática destes currículos prescritos, ou seja, o currículo então entendido como uma materialização intelectual das demandas globais, isto é, o projeto que se tem para a sociedade (SACRISTÁN, 2013), fortemente influenciado pelos interesses internacionais e empresariais que, pela égide da globalização, torna-se um braço do desenvolvimento do modo de produção capitalista, acaba por ser praticado nas escolas de cidades médias e pequenas, em nível local.

(...) reduzimos o currículo e o ensino a uma sequenciação do domínio de competências e a uma concepção pragmatista, utilitarista, cientificista e positivista de conhecimento e de ciência. Currículos presos a essa concepção tendem a secundarizar o conhecimento e a reduzir o conhecimento à aquisição de habilidades e competências que o pragmatismo do mercado valoriza. Terminamos por renunciar a ser profissionais do conhecimento, deixamos de ser instigados pelo conhecimento, sua dinâmica e seus significados e terminamos por não garantir o direito dos educandos ao conhecimento. O mercado é pouco exigente em relação aos conhecimentos dos seus empregados. O que valoriza é a eficácia no fazer. (ARROYO, 2007, p.26).

Portando, percebe-se que as demandas globais e nacionais, por meio do currículo, são praticadas nos espaços locais, que são as cidades médias e pequenas. Essa relação dialética, gera um conflito. E cabe aqui as seguintes indagações: a política federal realmente atende às demandas de um país continental como o Brasil? E o currículo Estadual abrange a diversidade de um estado como Minas Gerais? Ou ambos apenas abordam a questão da diversidade, igualdade e equidade, mas estão pautados realmente em padronizar?

No plano do discurso, em nível federal, a BNCC traz a ideia de que seus conteúdos oferecem a possibilidade de adequação às realidades locais e propõem ações, dentre elas a de: “contextualizar os conteúdos dos componentes curriculares, identificando estratégias para apresentá-los, representálos, exemplificá-los, conectá-los e torná-los significativos, com base na realidade do lugar e do tempo nos quais as aprendizagens estão situadas" (BRASIL, 2018, p. 16). Existe aqui um processo de contradição em pensar e propor uma homogeneização curricular para um país em que as condições de implementação serão diversificadas de acordo com as condições financeiras e humanas de cada sistema de ensino. 
Também em seu discurso, em nível estadual, o Novo Currículo de Minas Gerais aponta para a importância de elementos significativos do estado, como os 853 municípios; as 3.622 escolas estaduais; 8.751 escolas municipais e 3.778 escolas privadas, distribuídas por 47 regionais de ensino, o que gera uma soma de $86 \%$ de alunos matriculados em escolas públicas (MINAS GERAIS, 2018). Portanto, com uma maioria representativa matriculada em escolas públicas espalhadas pelo estado em uma diversidade enorme, o documento trata também em seu discurso sobre a diversidade do estado e, ao mesmo tempo, prescreve uma padronização de conteúdo.

\begin{abstract}
A diversidade regional do Estado de Minas Gerais é resultado de um processo histórico de ocupação do território marcado por diferentes fatores, desde aqueles de ordem socioeconômica até os naturais de clima e vegetação. Essa diversidade se traduz no que podemos entender como várias "Minas Gerais" dentro dos limites do estado, exigindo, portanto, diferentes formas de abordagem e atuação sobre a realidade mineira. De fato, a efetividade de qualquer iniciativa parte necessariamente da compreensão da realidade para a qual se propõe (MINAS GERAIS, 2018, p. 4).
\end{abstract}

Com o intuito de procurar responder às perguntas feitas anteriormente, a análise comparativa a seguir procurou investigar e comparar a política curricular federal, no caso a BNCC, da área de Geografia dos anos finais do Ensino Fundamental II. Tal análise procurou compreender se o documento possibilita ao professor adaptar os conteúdos lecionados às realidades das cidades médias e pequenas, conforme os questionários aplicados aos professores de Geografia da rede estadual que atuam nas cidades de Alfenas e Paraguaçu. Como resposta os professores podiam indicar mais que um documento, assim, 75\% indicou ter como maior referência o Currículo Referência de Minas Gerais, logo seguido da Base Nacional Comum Curricular, com 58\%. Esses números geram um questionamento, por que usar a BNCC, quando se tem o CRMG elaborado com base na BNCC? Levantamos a hipótese de que a imposição da BNCC é tão intensa que os gestores e professores consideram ela mais que o próprio currículo mineiro. Dado isso, será feito um paralelo com as respostas do questionário dos docentes de Geografia de Alfenas e Paraguaçu, com proposições feitas pelo pesquisador para habilidades da BNCC. O objetivo é poder direcionar e contribuir com possíveis caminhos para o ensino de Geografia da temática aqui tratada.

\title{
3. A BNCC, A PADRONIZAÇÃO DO ENSINO E O SILÊNCIO SOBRE AS CIDADES MÉDIAS E PEQUENAS
}

A Base Nacional Comum Curricular (BNCC) do Ensino Fundamental II, homologada em 2017, é considerada o marco atual para a educação, fornecendo as competências, habilidades e objetos do conhecimento a serem lecionados durante toda essa fase escolar.

Nesta etapa do Ensino Fundamental, o documento apresenta um discurso em consonância com um projeto que valoriza a autonomia do estudante, pode se perceber que um maior foco é dado para termos como projeto de vida e projeto para o futuro. 
Espera-se, assim, que o estudo da Geografia no Ensino Fundamental - Anos Finais possa contribuir para o delineamento do projeto de vida dos jovens alunos, de modo que eles compreendam a produção social do espaço e a transformação do espaço em território usado. Anseia-se, também, que entendam o papel do Estado-nação em um período histórico cuja inovação tecnológica é responsável por grandes transformações socioespaciais, acentuando ainda mais a necessidade de que possam conjecturar as alternativas de uso do território e as possibilidades de seus próprios projetos para o futuro. Espera-se, também, que, nesses estudos, sejam utilizadas diferentes representações cartográficas e linguagens para que os estudantes possam, por meio delas, entender o território, as territorialidades e o ordenamento territorial em diferentes escalas de análise (BRASIL, 2018, p. 381).

Compreender os fenômenos em diferentes escalas de análise, como diz a própria base, são um dos objetivos da Geografia no Ensino Fundamental. Entretanto, cabe indagar se, apesar de prever em seus objetivos, a base realmente proporciona essa visão escalar, elemento que deveria ser princípio de um documento nacional que será base para currículos estaduais e municipais.

A BNCC de Geografia destinada ao Ensino Fundamental II é subdividida em unidades temáticas, são elas: o sujeito e seu lugar no mundo; conexões e escalas; mundo do trabalho; formas de representação do pensamento espacial e natureza, ambientes e qualidade de vida. Ademais, cada uma das unidades temáticas é subdividida em objetos de conhecimentos e estes em habilidades. $\mathrm{Na}$ análise aqui apresentada buscou-se compreender se os conteúdos apresentados nessa organização possuem potencialidades de articulação com as dinâmicas socioespaciais presentes em cidades médias e pequenas, considerando sua relação global-local.

As habilidades da BNCC são codificadas por números e letras. Dessa maneira, usando como exemplo a habilidade EF06GE01, EF significa que é uma habilidade do Ensino Fundamental, 06 o ano escolar, logo, sexto ano, GE o componente curricular que é Geografia e 01 apenas a ordem, por ser a primeira, e assim sucessivamente em todas as habilidades dos anos escolares.

Na unidade temática "o sujeito e seu lugar no mundo", percebem-se que poucas habilidades possibilitam ao professor inserir as temáticas de cidades médias e pequenas.

(EF06GE01) Comparar modificações das paisagens nos lugares de vivência e os usos desses lugares em diferentes tempos.

(EF06GE11) Analisar distintas interações das sociedades com a natureza, com base na distribuição dos componentes físico-naturais, incluindo as transformações da biodiversidade local e do mundo (BRASIL, 2018, p. 382).

Quando trata das paisagens dos lugares de vivência e seus usos em diferentes tempos, a habilidade EF06GE01 possibilita ao professor em suas aulas fazer uma aproximação com a escala local, mesmo ainda que limitada. A habilidade EF06GE11, pertencente à unidade temática "natureza, ambientes e qualidade de vida", procura tratar da biodiversidade local e do mundo, o que pode dar uma aproximação para trabalhar a relação entre as escalas local e global, mas ainda de forma limitada, pois não há uma menção sobre cidades médias ou pequenas. É importante destacar que abordar a escala local não é a mesma coisa que abordar a dinâmica socioespacial das cidades, muitas vezes essa 
abordagem se limita a análise de fenômenos isolados e muitas vezes com uma visão nacional pautada no urbano das grandes cidades.

Entretanto, analisando a fala dos professores, no que se refere a abordar estas dinâmicas socioespaciais das cidades médias e pequenas, é possível notar uma variedade de abordagens em sala de aula e até mesmo de enxergar estas dinâmicas. Como, por exemplo, quando questionados sobre qual contexto urbano as escolas que lecionam estão inseridas (médias ou pequenas) e se isto interfere no processo de ensino-aprendizagem, o professor C disse: "Pequena, sempre destaco as questões locais", ficando evidente que tal professor pensa ser necessário somente exemplificar as questões locais, que é uma ação importante, mas não suficiente para entender as dinâmicas das cidades pequenas e médias. Já o professor D fala:

A escola que leciono situa-se em uma cidade média. No processo de ensino-aprendizagem tenho explorado a interação e análise dos alunos (as) sobre os fenômenos e fatores associados à produção do espaço e como este conceito se aplica no dia a dia destes estudantes.

Já na concepção deste docente, é possível notar que procura tratar não apenas da questão local, mas como esta está articulada às demais escalas pelo processo de produção do espaço e como isso influencia no cotidiano dos alunos.

Detalhe para a unidade "conexões e escalas", em que a análise identificou que em nenhuma habilidade há uma aproximação entre local e global ou até mesmo uma aproximação com padrões climáticos e físicos em escalas locais. O que há, no máximo, é uma comparação de escoamento nos ambientes rurais e urbanos, que dá a possibilidade de aproximar os alunos dos contextos de cidade médias ou pequenas, pois como visto, nessas cidades a relação entre o rural e urbano ocorre de forma bem mais intensa e deve ser melhor explorada. Mas isso vai depender de o professor superar a forma tradicional de abordar o rural e urbano, de forma fragmentada e hierarquizada. Vale lembrar que a unidade "conexões e escalas", até mesmo pelo nome, deveria explorar bastante as articulações globallocal, o que no $6^{\circ}$ ano pode ser concluído como insuficiente. Em suma, são tratados itens como estereótipos, fluxos populacionais, territorialidades, circulação de mercadoria, transportes, inovação e industrialização, os quais podem ser trabalhados em cidades médias e pequenas, porém, isso não é explícito. Desta forma, vai depender de como os currículos estaduais e municipais serão organizados e da formação do professor.

No $7^{\circ}$ ano, como é possível analisar, tanto cidades médias ou pequenas como a relação global-local são pouco ou praticamente nada exploradas, até mesmo na unidade temática "conexões e escalas",

(EF07GE12) comparar unidades de conservação existentes no Município de residência e em outras localidades brasileiras, com base na organização do Sistema Nacional de Unidades de Conservação (SNUC) (BRASIL, 1998, p. 385). 
Na habilidade EF07GE12, pertencente à unidade temática "natureza, ambientes e qualidade de vida", que trata sobre a comparação entre unidades de conservação presentes no município de residência e outras unidades do país, há realmente uma maior possibilidade de relacionar com a escala local, visto que possibilita comparações entre unidades de diferentes locais e, consequentemente, cidades maiores e menores, o que enseja trabalhar tanto com cidades médias ou pequenas, dependendo do contexto em que a escola está inserida. Mas, é importante que essa abordagem não se limite ao Parque Nacional em si, mas trate sobre como ele está inserido na dinâmica do município, como interfere no fluxo de pessoas, no comércio, na dinâmica natural, etc. Também possibilita trabalhar a relação com a escala federal, uma vez que faz menção ao Sistema Nacional de Unidades de Conservação da Natureza (SNUC). Assim, nota-se que no $7^{\circ}$ ano a possibilidade de se trabalhar a relação global-local e as cidades médias e pequenas ainda é bem reduzida, o que sugere um maior esforço por parte do docente em sala de aula para realizar tal aproximação.

No que tange ao $8^{\circ}$ ano, como pode ser constatado, existem habilidades que estimulam uma abordagem de fatos e situações do histórico das famílias com o município onde residem e oferecem ao docente a possibilidade de fazer uma aproximação principalmente entre as dinâmicas globais e locais de migração, como na habilidade EF08GE02: "Relacionar fatos e situações representativas da história das famílias do Município em que se localiza a escola, considerando a diversidade e os fluxos migratórios da população mundial" (BRASIL, 2018, p. 387).

Entretanto, ainda no $8^{\circ}$ ano, a análise de algumas habilidades permitiu identificar que a escala local fica à deriva, apesar desta pesquisa identificar a potencialidade de se explorar a questão globallocal de forma explícita, principalmente nas temáticas referente às questões urbanas, com habilidades que enfatizam as grandes cidades, como em EF08GE16: “Analisar as principais problemáticas comuns às grandes cidades latino-americanas, particularmente aquelas relacionadas à distribuição, estrutura e dinâmica da população e às condições de vida e trabalho" (BRASIL, 2018, p. 388).

Assim, fica claro que os fenômenos e acontecimentos abordados nas habilidades analisadas privilegiam as grandes cidades. Até mesmo em relação aos recursos hídricos, tratando das grandes usinas hidrelétricas e grandes bacias hidrográficas em detrimento das cidades médias e pequenas que são deixadas de lado, o que corrobora para um ensino de Geografia deslocado das realidades em que estão inseridos a maioria dos alunos. Quando a política curricular não trata a temática de forma explicita, ela contribui para que o professor tenha dificuldade de trabalhar tal conteúdo. Isso acontece com a temática de cidades médias e pequenas, apesar de grande parte do Brasil estar inserido neste contexto, são as metrópoles e grandes cidades que mais se destacam na BNCC, o que nos leva a questionar de qual nacional o documento trata.

O que se pensa é que não se deve nem priorizar somente a escala local das cidades médias e pequenas e nem as escalas nacionais e globais, mas sim que tais escalas se articulem, passando pela 
escala local das cidades médias e pequenas, pelas escalas regionais, nacionais e globais, mas sem utilizar o círculo concêntrico. O que permitiria ao aluno construir essa visão escalar entre local e global, percebendo que essas escalas estão conectadas pelo espaço geográfico em que ele se encontra inserido e atuante. Para isso, é necessário que o currículo e o professor levem os alunos a pensarem nas dinâmicas de cidades médias e pequenas, saindo do discurso do nacional que normalmente é pautado na metrópole.

Já no $9^{\circ}$ ano, temas como globalização e mundialização são frequentemente usados nos objetos de conhecimento e habilidades. No objeto de conhecimento "Integração mundial e suas interpretações: globalização e mundialização”, uma de suas habilidades trata o assunto da seguinte maneira: “(EF09GE05) Analisar fatos e situações para compreender a integração mundial (econômica, política e cultural), comparando as diferentes interpretações: globalização e mundialização" (BRASIL, 2017, p. 391). Se explorada mais a fundo, essa habilidade poderia tratar também das cidades médias e pequenas, pois, como já exposto, estão totalmente inseridas e fazem parte desse processo de globalização, sobretudo, no caso da cidade média de Alfenas, a qual, assim como outras cidades médias, apresenta considerável importância dentro do contexto técnicocientífico-informacional por abrigar universidades e centros de pesquisa.

Ademais, por ser um ano escolar em que a abordagem crítica é aprofundada, esperava-se mais, principalmente nos temas relativos à cultura, industrialização e globalização. Temas esses que de certa forma são tratados pela BNCC, entretanto, de uma forma mais superficial e, na maior parte, sem articulações com a escala local e com as cidades médias e pequenas, ou seja, com o espaço de vivência dos educandos, visto que, em suas habilidades, o que se presencia são temas mais genéricos e que buscam analisar fenômenos em escalas maiores, como mundial e nacional, deixando de lado escalas regionais e principalmente locais, o que, mais uma vez, fica a cargo dos docentes, como é possível ver nas habilidades EF09GE12 e EF09GE13.

(EF09GE12) relacionar o processo de urbanização às transformações da produção agropecuária, à expansão do desemprego estrutural e ao papel crescente do capital financeira em diferentes países, com destaque para o Brasil.

(EF09GE13) analisar a importância da produção agropecuária na sociedade urbano-industrial ante o problema da desigualdade mundial de acesso aos recursos alimentares e à matériaprima (BRASIL, 2018, p. 391).

Assim, percebe-se que a BNCC se caracteriza como pragmática, dividida em unidades temáticas e subdividida em objetos de conhecimento e habilidades enumeradas, havendo a separação para cada ano.

\section{CONSIDERAÇÕES FINAIS}


Em relação à articulação entre o global e o local, a BNCC aborda muito pouco essa questão. O referido documento trata apenas no começo de sua descrição sobre as unidades temáticas e, como visto, aparece muito pouco em habilidades que seriam essenciais para a compreensão dos fenômenos geográficos. O documento indica a necessidade de trabalhar o lugar de espaço de vivência dos alunos e também a escala global, no entanto, falta pensar na articulação dessas escalas de forma mais explícita e a abordagem das cidades médias e pequenas pode ser um dos caminhos a ser utilizado.

Quanto à abordagem das cidades médias e pequenas, fica evidente que na BNCC, pelo seu caráter pragmático e menos amplo, ou seja, com considerações de ordem mais prática; realista, objetiva, sem articulações e com sua visão nacional pautada em metrópoles e cidades grandes, dificulta a articulação entre as escalas global-local e a abordagem das dinâmicas de cidades médias e pequenas nas aulas de Geografia. Analisando a relação do professor com o currículo, Arroyo afirma que:

Consequentemente, o currículo é o polo estruturante de nosso trabalho. As formas em que trabalhamos, a autonomia ou falta de autonomia, as cargas horárias, o isolamento em que trabalhamos... dependem ou estão estreitamente condicionados às lógicas em que se estruturam os conhecimentos, os conteúdos, matérias e disciplinas nos currículos (ARROYO, 2007, p.18).

Com relação a isso, ainda sobre a pergunta da relação entre o contexto de cidades médias e pequenas e sua relação com ensino-aprendizagem, o professor E comenta: "Média. Cidades pequenas existe uma maior aproximação entre pais, mães e escola. Na cidade pequena muitos se conhecem, é mais fácil formar uma comunidade escolar, o envolvimento entre família e escola é melhor e isso tem influência no aprendizado das crianças". Nesta fala, é importante destacar que, mesmo atuando em uma cidade média, o professor conseguiu perceber que no contexto de uma cidade pequena, provavelmente por já ter atuado em uma, há um maior envolvimento da comunidade escolar, o que se torna de grande relevância, visto que é necessário que o docente conheça o contexto socioespacial em que atua. Entretanto, muitas vezes isso não é levado em conta no processo de ensinoaprendizagem.

Por mais que o professor tenha a função de contextualizar o conteúdo e adaptar à realidade do aluno, quando os documentos oficiais omitem conteúdos, estão contribuindo para que esse não seja abordado nas aulas. Outro elemento que contribui é que as pesquisas sobre cidades médias e pequenas são relativamente recentes e muitos professores se formaram sem se aprofundar nessa discussão teórica, o que dificulta a abordagem da temática no ensino de geografia.

Foi possível constatar a consonância entre o discurso das instituições internacionais e nacionais em consolidação com a criação e homologação da Base Nacional Comum Curricular (BNCC), em 2018, e do Currículo Referência de Minas Gerais, também no mesmo ano, juntamente com a aprovação das Diretrizes Curriculares de Formação de Professores, em 2019, deixando 
evidente essa articulação entre as políticas curriculares, a formação de professores e os interesses internacionais em educação. Desse modo, fica claro que as políticas curriculares formuladas e influenciadas pelos interesses neoliberais globais irão atingir as escalas locais das cidades médias e pequenas, pois serão referência para os professores de diversas cidades em sala de aula, como no caso do estado de Minas Gerais.

\section{REFERÊNCIAS}

ARROYO, M. G. Indagações sobre currículo: educandos e educadores: seus direitos e o currículo. In: BEAUCHAMP, J.; PAGEL, S. D.; NASCIMENTO, A. R. (Orgs.). Organização do Documento. Brasília: Ministério da Educação, 2007. p. 1-52.

BRASIL. Lei no 9.394, de 20 de dezembro de 1996. Estabelece as Diretrizes e Bases da educação Nacional. Diário Oficial da República Federativa do Brasil, Brasília, v. 23, 1996.

BRASIL. Plano Nacional de Educação 2014-2024. Lei n⿳ 13.005, de 25 de junho de 2014, que aprova o Plano Nacional de Educação (PNE) e dá outras providências. Brasília: Câmara dos Deputados, Edições Câmara, 2014. 86p.

CALLAI, H. C.; CAVALCANTI, L. S.; CASTELlAR, S. M. V. Lugar e cultura urbana: um estudo comparativo de saberes docentes no Brasil. Terra Livre, v. 1, n. 28, p. 91-108, 2007.

CASTELLAR, S. M. V. Currículo, educação geográfica e formação docente: desafios e perspectivas. Revista Tamoios, v. 2, n. 2, p. 1-17 2010.

CAVALCANTI, L. S. Aprender sobre a cidade: a geografia urbana brasileira e a formação de jovens escolares. Revista Geográfica de América Central, v. 2, n. 5, p. 1-18, 2011.

CEPAL, N. U. Educación, juventud y trabajo Habilidades y competencias necesarias en un contexto cambiante. Santiago: CEPAL, 2020. 115p.

DELORS, J.; NANZHAO, Z. Educação um tesouro a descobrir. São Paulo: Cortez, 1988. 281p.

FRESCA, T. M. Em defesa dos estudos das cidades pequenas no ensino de Geografia. Geografia (Londrina), v. 10, n. 1, p. 27-34, 2001.

FRESCA, T. M. Centros locais e pequenas cidades: diferenças necessárias. Mercator, v. 9, n. 20, p. 75-81, 2010.

GIROTTO, E. D. Dos PCNs a BNCC: o ensino de Geografia sob o domínio neoliberal. Geo Uerj, v. 6, n. 30, p. 419-439, 2017.

IBGE - INSTITUTO BRASILEIRO DE GEOGRAFIA E ESTATÍSTICA. SIDRA. Censos demográficos, 1980, 1991, 2000 e 2010.

LACERDA, C. C.; SEPEL, L. M. N. Percepções de professores da Educação Básica sobre as teorias do currículo. Educação e Pesquisa, v. 45, n 12, p. 14-29, 2019. 
MACEDO, E. Base Nacional Comum Curricular: novas formas de sociabilidade produzindo sentidos para educação. Revista E-curriculum, v. 12, n. 3, p. 1530-1555, 2014.

MINAS GERAIS. Currículo Básico Comum (CBC). Proposta Curricular, 2007.

MINAS GERAIS. Currículo Referência de Minas Gerais. 2019. Disponível em: http://basenacionalcomum.mec.gov.br/images/implementacao/curriculos_estados/documento_curri cular_mg.pdf. Acesso em: 02 fev. 2018.

MINAS GERAIS. SECRETARIA DE ESTADO DE EDUCAÇÃO. Resolução SEE No 2.197, de 26 de outubro de 2012. Dispõe sobre a organização e o funcionamento do ensino nas Escolas Estaduais de Educação Básica de Minas Gerais e dá outras providências. Disponível em: https://www.educacao.mg.gov.br/images/documentos/2197-12-r.pdf. Acesso em: 15 dez. 2017.

MINAS GERAIS. SECRETARIA DE ESTADO DE EDUCAÇÃO. Resolução SEE $\mathbf{N}^{\mathbf{0}} \mathbf{2 8 3 6}$, de 28 de dezembro de 2015. Estabelece normas para a organização do Quadro de Pessoal das Escolas Estaduais e a designação para o exercício de função pública na Rede Estadual de Educação Básica no ano de 2016 e dá outras providências. Disponível em: https://www.educacao.mg.gov.br/images/documentos/2836-15-r.pdf. Acesso em: 15 dez. 2017.

MOTA JUNIOR, W. P.; MAUÉS, O. C. O Banco Mundial e as políticas educacionais brasileiras. Educação \& Realidade, v. 39, n. 4, p. 1137-1152, 2014.

OLIVEIRA, C. M. As influências do Banco Mundial na Política Educacional: o foco na educação e na regulação social. In: REUNIÃO CIENRÍFICA DA ANPED. 11., 2016, Curitiba. Anais... Curitiba: UFPA, 2016. p. 1-16.

SACRISTÁN, J. G. Saberes e incertezas sobre o currículo. Penso Editora, 2013. 542p.

SACRAMENTO, A. C. R. O estudo da cidade e do cidadão: A classe como intervenção didática para ensinar geografia. Revista Geográfica de América Central, v. 1, n. 58, p. 101-123, 2017.

SANTOS, M. A abordagem das políticas públicas educacionais para além da relação estado e sociedade. In: SEMINÁRIO DE PESQUISA EM EDUCAÇÃO DA REGIÃO SUL. 9., 2012, Caxias do Sul. Anais... Caxias do Sul: UCS, 2012. p. 1-16.

TADEU, T. Documentos de identidade: uma introdução às teorias do currículo. São Paulo: Autêntica. 2016. 237p.

TRICHES, E. F.; ARANDA, M. A. M. A formulação da base nacional comum curricular (BNCC) como ação da política educacional: breve levantamento bibliográfico (2014-2016). RealizAção, v. 3, n. 5, p. 81-98, 2016.

WORLD BANK. Priorities and Strategies for Education: A World Bank Review. Development in Practice Series. Washington: ERIC Clearinghouse, 1995. 196p. 